\title{
The Impact of the Covid-19 Pandemic on Global Population Ageing
}

\author{
Sarah Harper ${ }^{1}$
}

Accepted: 27 April 2021/ Published online: 22 May 2021

(C) The Author(s), under exclusive licence to Springer Nature B.V. 2021

There is widespread speculation over the impact of the Covid-19 pandemic on demographic trends. Baby boom or baby bust? Lowest life expectancy for half a century? The reality is likely to be complex and nuanced. Given that population ageing is driven by fertility and mortality trends, the impact of the current pandemic on demographic trends is clearly important to our understanding of future ageing societies.

\section{Boom or Bust}

Current data from Europe and the US suggest a sharp fall in births by the end of 2020. Both Italy and Spain, for example, saw a $20 \%$ fall in the monthly number of births between December 2019 and December 2020, the latter month recording Spain's lowest monthly level since comparable records began in 1941. Even pro-natal France experienced a $13.3 \%$ fall in births in January 2021, the biggest month-on-month drop in 45 years. And in the USA, current falls suggest a decline of up to half a million births in 2021 (Kearney and Levine, 2020). This is also reflected in the TFR, with England and Wales recording a low of 1.66 , Scotland 1.37 , and Italy falling to 1.27 . While these trends have been downward in recent years, the declines seen in 2020 into 2021 are particularly remarkable. These trends are also corroborated by survey research which suggests that over a third of women in both the US (Lindberg et al. 2020) and several European countries (Italy, France, Germany, Spain and the UK) (Luppi et al., 2020) plan to postpone giving birth or have fewer children as a result of the pandemic.

The classic response to a pandemic is a steep decline in births, followed by a gradual increase, then a so-called baby-boom. We saw this after the Spanish Flu pandemic of 1918-19. Spanish flu killed more than 50 million people globally (Jester et al. 2018), followed by a baby boom in 1920 as young people rushed to get married and start a family, arguably as a result of surviving the pandemic (Mamelund, 2004;

Sarah Harper

sarah.harper@ageing.ox.ac.uk

1 Oxford Institute of Population Ageing, University of Oxford, Oxford, UK 
Mamelund, 2012). And again more recently following SARS (Lee et al., 2005) and Ebola (McBain et al., 2016).

However, the Covid-19 pandemic does not have the classic drivers to create a baby boom. While, the 1918 pandemic saw high mortality among the young and those of childbearing age, deaths from Covid-19 have focused on older adults. Thus the desire to replace children, or an obligation to reproduce given a high death rate among your peers, is not present today among those of childbearing age as few children and those of reproductive age have died. Rather, this generation of potential parents has been more affected by lockdowns and Long Covid, both of which have had a significant impact on physical and mental health, particularly of women. Women suffering from Long Covid may decrease their child bearing due to chronic ill health, and there is also evidence that the desire for parenthood in some European countries may even have fallen (Micelli et al., 2020).

The situation post Covid-19 is thus likely to be defined not by classic pandemic drivers, but by the significant economic downturn which was stimulated by the public health response - loss of employment and home, and anxiety and fear for the future are likely to frame the outlook of many young people today. It is therefore necessary to look to the outcomes following a recession to find indications of future fertility trends and patterns.

While the impact of the pandemic, and particularly the various lockdowns, vary across the globe, millions of adults have been unable to work and unemployment rates have increased significantly (Abedi et al., 2020; Zhang and Schwartz 2020; Banik et al., 2020). As a result, there is a predicted global economic contraction of $7 \%$, with LMICs most affected (World Bank, 2020). This has led to increased physical and mental stress (Pérez-Escamilla et al., 2020; Pfefferbaum \& North, 2020). There is widespread evidence that child bearing rates are affected by economic downturns and recessions, with a clear association between loss of employment and earnings and a fall in fertility rates (Autor et al. 2019).

There is one issue which is of particular concern, namely reports of a lack of contraception in LMICs which may increase childbearing with an increase in unwanted briths. Analysis conducted for 115 low- and middle-income countries in January 2021 by UNFPA (2021) suggested that the impact of COVID-19 on access to health services is ongoing. An estimated 12 million women may have been unable to access family planning services as a result of the pandemic. As a result of these disruptions, as many as 2.7 million unintended pregnancies may have occurred before women were able to resume use of family planning services.

\section{Decreasing Life Expectancy, or Just Healthy Life Expectancy?}

What about mortality increase, which has seen considerable hyperbole? Most of the estimations are cross-sectional and it is thus likely that the immediate high mortality rates of the pandemic will not be translated into long term reductions in life expectancy. This can be seen in previous mortality hits, such as the 1918 pandemic, where life expectancy recovered and continued to increase (Fig. 1). 


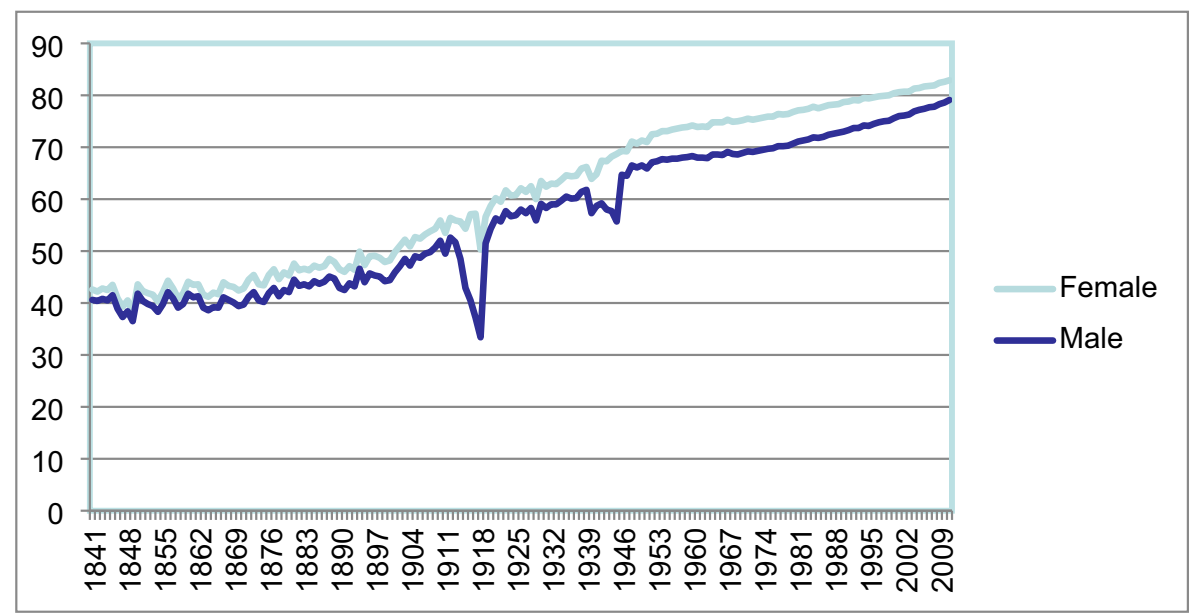

Fig. 1 Life expectancy at birth for males and females in England and Wales, 1841-2010. Source: Leeson 2014

A detailed early review by Marois et al. (2020) points out that estimating the impact of the COVID-19 epidemic on the life expectancy of a population is complex and not clear cut.

On the one hand, as the virus kills a disproportionate number of people in the older population, the number of years lost with respect to existing average life expectancy might be smaller than expected. On the other hand, the rapid spread of the virus might cause a high level of excess mortality, as observed in many European countries that is consistently large enough to affect the lifetable of a country or region.

In the absence of the pandemic, life expectancies for men and women combined in 2020 were expected to be 79.2 years in North America and Europe, 76.1 years in Latin America and the Caribbean, 73.3 years in south eastern Asia and 62.1 years in subSaharan Africa. The estimated loss in life expectancy depends on different combinations of age-specific fatality rates and prevalence rates assumptions. For example, in North America, Europe, Latin America and the Caribbean, each percentage increase in the prevalence of Covid-19 infection would reduce life expectancy by about 0.1 year. At an infection prevalence of $10 \%$, a little over one year of life expectancy is lost, and at $50 \%$ of infection prevalence, about 5 years are lost. In both south eastern Asia and sub-Saharan Africa, the impact of Covid-19 on the period life-expectancy would be lower. Thus loss in life expectancy in sub-Saharan Africa would be half of that in North America and Europe.

As a result, Marois et al. (2020) predict that at the upper limit of their estimates, 11 years of life expectancy would be lost in North America and Europe, 10 years in Latin America and the Caribbean, 8 years in south eastern Asia and 5 years in subSaharan Africa. 
Life expectancy in North America and Europe could become comparable to what has been observed in Brazil in recent years, while such a loss could temporarily set Latin America and the Caribbean back to the life expectancy they had 20 years ago.....

HICs might see life expectancy fall to below 70 years, which is equivalent to the life expectancy of Western Europe in the mid twentieth Century.

Similar detailed analysis has been carried out at the country level. Aburto et al. (2020) explore the impact for England and Wales. The UK, like many other high income countries, has shown recent reversals and stagnation in life expectancy, with explanations suggesting mid-life mortality crisis and a growth in national inequalities. The pandemic has changed this for the present, with a sharp increase in older age mortality, and, partly as a result of this, a reduction in life-span mortality inequality.

Clearly, the massive loss of older lives has led to a sharp decrease in life expectancy globally, but one which may bound back as the deaths of those lives prematurely lost during the pandemic will not figure in the future mortality tables. Looking to the future, however, it is also clear that it is the wider context of the pandemic which will have longer implications.

Covid-19 has had a significant impact on most health care systems across the globe, and especially those in LMICs (Shuchman, 2020; Roberton, et al. 2020). Furthermore, fear of Covid-19 plus awareness of the over stretched health care systems have deterred people from getting treatments. In addition, the above mentioned economic downturn will also have an impact on the health profile of different populations, particularly in LMICs (Willaims, et al. 2016; Arroyave et al., 2015). All these contextual drivers are likely to lead to higher mortality from other diseases and chronic conditions such as cancer and cardio-vascular disease ( Ji et al., 2020 Hanna et al. 2020). In addition, Covid19 has impacted unequally, particularly affecting poorer, deprived populations, which will increase future health inequalities (Bambra et al., 2020) and (Trias-Llimós, 2020).

Finally, there is the currently unknown impact of Long Covid, the increased morbidity and chronic conditions which appear to effect up to one third of those infected with the disease, including one in three people with Covid receiving a formal neurological or psychiatric diagnosis within six months of infection according to a recent study (Taquet et al., 2021). However, it is likely that this will also lead to lower LE and in particular lower HLE (Mahase, 2020). It is thus unclear how long the lower life expectancy levels will continue beyond the short term and even medium term, and what the mortality profile will eventually comprise.

While future estimations of trends arrive with caveats, it seems that many countries will experience a period of falling fertility and lower healthy life expectancy, than would have been the case if the pandemic had not arisen, though for how long is unclear. Additionally, while the widespread increase in late-life mortality has affected all socio-economic groups, the longer term increases in morbidity and mortality are likely to be weighted towards those with higher levels of deprivation, compounding the already evident social gradient in mortality. Falling fertility, especially in HICs, combined with lower HLE, will exasperate the potential problems which may arise with demographic ageing. Sicker, potentially poorer, more unequal populations, will need radical rethinking to return to the previous optimism in tackling the challenge of ageing populations. 


\section{References}

Abedi, V., Olulana, O., Avula, V., Chaudhary, D., Khan, A., Shahjouei, S., Li, J., \& Zand, R. (2020). Racial, economic, and health inequality and COVID-19 infection in the United States. J Racial Ethnic Health Dispar. https://doi.org/10.1007/s40615-020-00833-4.

Aburto, JM, Kashyap, R., Schley, J., Angus, C., and Ermish, J. et al (2020) Estimating the burden of COVID19 pandemic on mortality, life expectancy and lifespan inequality in England and Wales: A populationlevel analysis (pre-print).

Arroyave, I., Hessel, P., Burdorf, A., Rodriguez-Garcia, J., Cardona, D., \& Avendaño, M. (2015). 2015 the public health impact of economic fluctuations in a Latin American country: Mortality and the business cycle in Colombia in the period 1980-2010. International Journal for Equity in Health, 14, 48.

Autor, D., Dorn, D., \& Hanson, G. (2019). When work disappears: Manufacturing decline and the falling marriage market value of young men. American Economic Review: Insights, 1(2), 161-178.

Bambra, C., Riordan, R., Ford, J., \& Matthews, F. (2020). The COVID-19 pandemic and health inequalities. Journal of Epidemiology and Community Health, 74, 964-968. https://doi.org/10.1136/jech-2020214401.

Banik, R., Rahman, M., Sidker, M. T., \& Gozal, D. (2020). SARS-CoV-2 pandemic: An emerging public health concern for the poorest in Bangladesh. Public Health in Practice., 1, 100024. https://doi.org/10. 1016/j.puhip.2020.100024.

Hanna, T. P., King, W. D., Thibodeau, S., Jalink, M., Paulin, G. A., Harvey-Jones, E., O’Sullivan, D. E., Booth, C. M., Sullivan, R., \& Aggarwal, A. (2020). Mortality due to cancer treatment delay: Systematic review and meta-analysis. BMJ, 371. https://doi.org/10.1136/bmj.m4087.

Jester, B., Uyeki, T., \& Jernigan, D. (2018). Readiness for responding to a severe pandemic 100 years after 1918. American Journal of Epidemiology, 187, 2596-2602. https://doi.org/10.1093/aje/kwy165.

Ji, Y., Ma, Z., Peppelenbosch, M. P., \& Pan, Q. (2020 Apr 1). Potential association between COVID-19 mortality and health-care resource availability. The Lancet Global Health., 8(4), e480. 32109372.

Kearney, M. and Levine, P. (2020) The coming COVID-19 baby bust: Update December 2020, Brookings.

Lee, C. H., Huang, N., Chang, H. J., Hsu, Y. J., Wang, M. C., \& Chou, Y. J. (2005). The immediate effects of the severe acute respiratory syndrome (SARS) epidemic on childbirth in Taiwan. BMC Public Health, 5, 30. https://doi.org/10.1186/1471-2458-5-30.

Leeson, G. W. (2014). Increasing Longevity and the New Demography of Death. International Journal of Population Research, 2014, 521523-521527. https://doi.org/10.1155/2014/521523.

Lindberg, L. D., et al. (2020). Early impacts of the COVID-19 pandemic: Findings from the 2020 Guttmacher Survey of Reproductive Health Experiences. New York: Guttmacher Institute https://www.guttmacher. org/report/early-impacts-covid-19-pandemic-findings-2020-guttmacher-survey-reproductive-health.

Luppi, F., Arpino, B., \& Rosina, A. (2020). The impact of COVID-19 on fertility plans in Italy, Germany, France, Spain, and the United Kingdom. Demographic Research, 43, 1399-1412.

Mahase, E. (2020). Covid-19: What do we know about "long covid"? BMJ, 370. https://doi.org/10.1136/bmj. $\mathrm{m} 2815$.

Mamelund, S. E. (2004). Can the Spanish influenza pandemic of 1918 explain the baby boom of 1920 in neutral Norway? Population., 59, 229-260. https://doi.org/10.3917/pope.402.0229.

Mamelund, S. E. (2012). Fertility fluctuations in times of war and pandemic influenza. The Journal of Infectious Diseases, 206, 140-141. https://doi.org/10.1093/infdis/jis315.

Marois, G., Muttarak, R., \& Scherbov, S. (2020). Assessing the potential impact of COVID-19 on life expectancy. PLoS One, 15(9), e0238678. https://doi.org/10.1371/journal.pone.0238678.

McBain, R. K., Wickett, E., Mugunga, J. C., Beste, J., Konwloh, P., \& Mukherjee, J. (2016). The post-Ebola baby boom: Time to strengthen health systems. Lancet., 388, 2331-2333. https://doi.org/10.1016/S01406736(16)31895-5.

Micelli E, Cito G, Cocci A, Polloni G, Russo GI, Minervini A, et al. Desire for parenthood at the time of COVID-19 pandemic: an insight into the Italian situation. J Psychos Obstetr Gynecol. (2020) 5:1-8. doi: https://doi.org/10.1080/0167482X.2020.1759545

Pérez-Escamilla, R., Cunningham, K., \& Moran, V. H. (2020). COVID-19, food and nutrition insecurity and the wellbeing of children, pregnant and lactating women: A complex syndemic. Maternal \& Child Nutrition, 16, e13036. https://doi.org/10.1111/mcn.13036.

Pfefferbaum, B., \& North, C. S. (2020). Mental health and the Covid-19 pandemic. The New England Journal of Medicine, 383, 510-512. https://doi.org/10.1056/NEJMp2008017.

Roberton, T., Carter, E. D., Chou, V. B., Stegmuller, A. R., Jackson, B. D., Tam, Y., Sawadogo-Lewis, T., \& Walker, N. (2020 Jul 1). Early estimates of the indirect effects of the COVID-19 pandemic on maternal 
and child mortality in low-income and middle-income countries: A modelling study. The Lancet Global Health., 8(7), e901-e908. 32405459.

Shuchman, M. (2020 May 21). Low- and middle-income countries face up to COVID-19. Nature Medicine https://www.nature.com/articles/d41591-020-00020-2.

Taquet, M.,, John R Geddes, Masud Husain, Sierra Luciano, Paul J Harrison, 6-month neurological and psychiatric outcomes in 236379 survivors of COVID-19: A retrospective cohort study using electronic health records, The Lancet Psychiatry, V 8, Issue 5, 2021, https://doi.org/10.1016/S2215-0366(21)00084$5,416,427$.

Trias-Llimós, S., Riffe, T., \& Bilal, U. (2020). Monitoring life expectancy levels during the COVID-19 pandemic: Example of the unequal impact of the first wave on Spanish regions. PLoS One, 15, e0241952. https://doi.org/10.1371/journal.pone.0241952.

UNFPA, (2021) Impact of COVID-19 on Family Planning: what we know one year into the pandemic, Technical note, March 2021.

Williams, C., Gilbert, B. J., Zeltner, T., Watkins, J., Atun, R., \& Maruthappu, M. (2016). Effects of economic crises on population health outcomes in Latin America, 1981-2010: An ecological study. BMJ Open, $2016,6 \mathrm{e} 007546$.

World Bank (2020) The Global Economic Outlook During the COVID-19 Pandemic: A Changed World, June 2020.

Zhang, C. H., \& Schwartz, G. G. (2020). Spatial disparities in coronavirus incidence and mortality in the United States: An ecological analysis as of may 2020. The Journal of Rural Health, 36, 433-445. https:// doi.org/10.1111/jrh.12476.

Publisher's Note Springer Nature remains neutral with regard to jurisdictional claims in published maps and institutional affiliations. 